\title{
Cross-linguistic Variation of Binding Possibilities and Parameterized DP Hypothesis Revisited
}

\author{
Zhang Zhiyi \\ School of Foreign Languages and Cultures Institute, Nanjing Normal University, Nanjing, China \\ Correspondence: Zhang Zhiyi, School of Foreign Languages and Cultures Institute, Nanjing Normal University, \\ No122 Ninghai Road, Nanjing, China Tel: 025-85891054. E-mail: maccarthy_2000@sohu.com
}

Received: January 31, 2019

Accepted: February 15, 2019 Online Published: March 15, 2019

doi:10.5430/elr.v8n1p37

URL: https://doi.org/10.5430/elr.v8n1p37

\begin{abstract}
The former study approached the cross-linguistic variation of binding possibilities from the perspective of parameterized DP hypothesis. However, the parameterized DP hypothesis failed to explain some syntactic truth as regards the binding relation between possessive NP and pronoun. It has been examined in the present study that different languages have different means to form possessive structure and different mechanisms work in obligatory and optional binding. The c-commanding relation is the semantic basis for the optional binding between the possessive NP and the pronoun. For languages with possessive NP entering derivation after T, possessive NP fails to c-command pronoun and there will be no optional binding. For languages with possessive NP or morpheme entering derivation before T, possessive NP or morpheme succeeds to c-command pronoun and there is optional binding.
\end{abstract}

Keywords: c-commanding, cross-linguistic variation, possessive NP, optional binding

\section{Introduction}

As one of the most classical theories of generative transformational (GT) grammar since its booming in 1980s (Chomsky, 1981: 670-699), binding theory keeps its vitality in spite of theoretical alternations made to GT (Webelhuth, 1995) due to its explanatory power. With the advancement of binding theory, many syntactic problems concerning the semantic and syntactic reference have been successfully solved, while some other syntactic phenomena still need to be optimized by structural analysis, among which the cross-linguistic variation of dual anaphor is such a tricky problem that might be tentatively investigated under binding theory. The cross-linguistic variation of dual anaphor can be exemplified as follows.

English

1. John's father considers himself intelligent.

2. $\mathrm{John}_{i}$ 's father considers $\operatorname{him}_{j}$ intelligent.

3. $\mathrm{John}_{i}$ 's father considers $\operatorname{him}_{i}$ intelligent.

Chinese

4. 小明的爸爸认为他自己聪明.

Xiaomingde baba renwei ta ziji congming

Xiaoming POSS father consider him REFLEXIVE intelligent

'Xiaoming's father considers himself intelligent.'

5. 小明 $i$ 的爸爸认为他 $j$ 聪明.

Xiaomingde baba renwei ta congming

XiaomingPOSSfather consider him intelligent

'Xiaomingi's father considers himj intelligent.'

6. *小明 $i$ 的爸爸认为他 $i$ 聪明.

Xiaomingde baba renwei ta congming 
XiaomingPOSS father consider him intelligent

'Xiaomingi's father considers himi intelligent.'

As can be clearly seen from the above sentences, cross-linguistic variation between English and Chinese shows typological difference as for the co-reference between the pronoun and the possessive NP. In sentence 1 and 4, the anaphor is locally bound by the head of the antecedent NP and the Binding Condition A requires the anaphor to be in reflexive form, leading to "himself" in English and “他自己 (taziji, 'himself')" in Chinese. The story is not the same in sentence 2, 3,5 and 6. For 2 and 3, the possessive NP "John" and the pronoun are not in the same local domain and according to Binding Condition B, the pronoun can refer back to NP "John" and thus be an anaphor. But the same does not apply to Chinese 5 and 6 in that 他(ta, 'him')cannot refer back to "Xiaoming" and thus cannot be an anaphor as exemplified in the ungrammatical sentence 6 .

Such cross-linguistic variation of co-reference relation between pronoun and the possessive NP is often explained under the parameterized DP hypothesis (see section 2 for more). Strictly speaking, the parameterized DP hypothesis, however, fails to reveal some important syntactic truths. Given the above, present study attempts to deal with the multifaceted theoretical issues. First, parameterized DP approach to cross-linguistic variation and its problems are introduced; Second, relation between different forms of possessives and different binding possibilities of possessive NP is explored. Third, different syntactic mechanisms of dual anaphor are discussed. Lastly, cross-language variation of binding possibilities is examined to exhibit the structural differences.

\section{Literature Review}

The parameterized DP hypothesis was first proposed by Fukui (1988: 249-270) and then further discussed by Zlatic (1997) and Boskovic (2009). The main argument of this hypothesis is that there exist parameter differences across languages. More specifically, for languages like Japanese and Serbian, the parameter is set as the DP layer is absent; while the same does not hold for English, given that the parameter is set as the DP layer is present. Following Kayne (1994), Despic $(2011,2013)$ attempted to explain the difference of binding possibilities of prenominal possessive NP by adopting parameterized DP analysis. Like Chinese, in Serbian, a pronoun cannot be bound by a prenominal possessive NP and thus cannot refer back to that possessive NP as exemplified by the following sentences.

7. $\mathrm{John}_{i}$ 's father considers $\operatorname{him}_{i}$ highly intelligent.

8. * Markov $_{i}$ otac smatra njega $i$ veoma pametnim.

Marko poss father considers him very intelligent

'Marko ${ }_{i}$ 's father considers him $_{i}$ very intelligent.'

Despic (2013) assumes the combination of parameterized DP hypothesis and c-commanding theory can satisfactorily explain the cross-linguistic variation between English and Serbian in the binding possibilities. The structural difference between sentence 7 and 8 can be exhibited by tree 1 and tree 2 respectively.

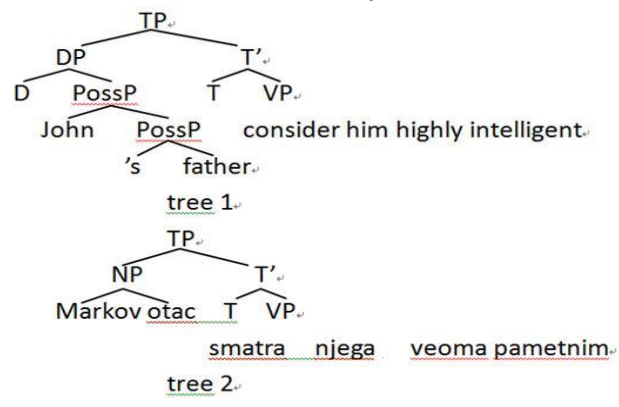

In tree 1, the English phrase "John's father" is in essence a DP within a DP layer, which seems to prevent NP "John" from c-commanding "him", which makes the co-reference of "John" and "him" possible; otherwise, the reflexive "himself" should be used. By contrast, in tree 2, the Serbian phrase "Markov otac" is in essence an NP without a DP layer. The lack of DP leads to the c-commanding relation between "Markov" and "njega". Hence the sentence is ungrammatical in sense that the reflexive should be used.

However, like what Laterza (2016: 741-753) pointed out, the argument made by Despic (2013) had some problems. In 9, a demonstrative can be added to Serbian prenominal possessive NP and the co-reference of "Marko" and "njega" is still not allowed. 
9. *Ovaj Markov drugs matra njega $_{i}$ veoma pametnim.

This Marko poss friend considers him very intelligent

'This friend of Marko $_{i}$ considers him $i$ very intelligent.'

In Slavic languages, the demonstrative functions as D(eterminer). According to Despic (2013), the DP layer helps to prevent the c-commanding relation from being established, since "Marko" fails to c-command "Njiga", it can be predicted that "Njiga" can refer back to "Marko". This proves to be wrong. Laterza's (2016) argument is convincing because the unacceptability of sentence 9 strongly implies that the different binding potentials cannot be attributed to either the presence or absence of DP layer between two languages. But unfortunately, though Laterza (2016: 749) suggested "it is some property of Serbian prenominal possessives in particular that is for the non-coreference fact" in sentence 9 , little is known about its syntactic property.

Besides, the structural description of tree 1 is not without its own problem (Lowe, 2015:1-39). To compare the following two sentences,

10. John's father ${ }_{i}$ considers himself $i_{i}$ intelligent.

11. The father ${ }_{i}$ of John considers himself $f_{i}$ intelligent.

The above two sentences have almost identical structures only except that in sentence 10, the DP layer of the prenominal possessive DP is empty; but in sentence 11, the DP layer is occupied by "the". Suppose the c-commanding is uni-direction, viz. rightward-directed, then for the first, how did "father" at the bottom layer in tree 3 succeed in establishing the co-reference relation with "himself"? For the second, why did the bottom layer NP "John" in tree 4 fail to establish co-reference relation?

In this sense, both the binding possibilities and the cross-linguistic structural differences have to be clarified to ensure the contributing property of pre-nominal possessive NP that leads to different binding possibilities.

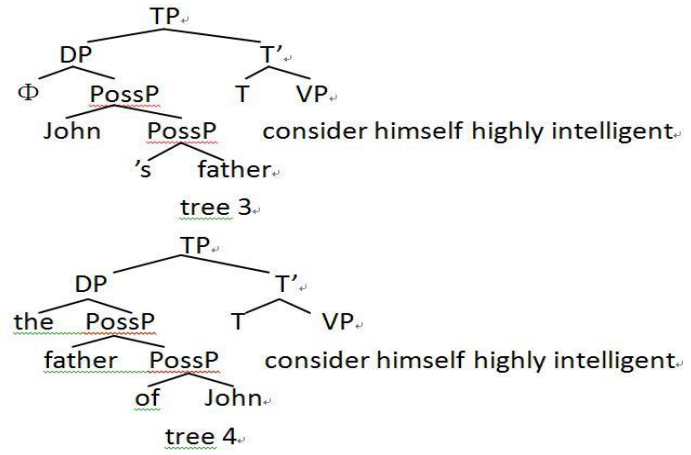

\section{Linguistic Data Analyses}

In a broad sense, a possessive is normally a word or grammatical construction used to indicate a relationship of possession (Wang and $\mathrm{Xu}, 2013$ : 1-30). The typological study of possessives suggests there might be four different ways to form the possessive relations, which will be explicated in details.

First, the use of clitic is applied to form possessive, as exemplified in English, which makes the binding possible. The English clitic"-'s" or a simple"-"” indicating possessive evolved from possessive case marker. However, linguists tend to consider "-'s" or "-"” a clitic rather than a possessive case marker simply in that it should be suffixed to the head NP. In English complex NP phrase like "The king of Spain's daughter", “-'s" is located immediately after the complement NP "Spain" as opposed to the head NP "king". This syntactic truth reveals that English "-'s" or a simple"-" should be identified as a clitic instead of a possessive case marker. For English clitic type of possessive structure, binding of the possessive NP is possible.

Second, suffix is added as a possessive case marker, which can be exemplified in Slavic languages like Russian, Serbian, Bulgarian and Macedonian. Among the Slavic languages, the order and binding possibilities are differently parameterized. In north Slavic languages like Russian, the possessive NP with possessive case marker is located after the head NP, and for this post-nominal possessive NP, binding is possible. In south Slavic languages like Serbian, Bulgarian and Macedonian, the case marked possessive NP is prenominal, and binding is impossible.

Russian 
12. Отец Джона $і$ счнтает его $i$ умным.

Father John Poss think him smart

'John ${ }_{i}$ 's father considers $\operatorname{him}_{i}$ intelligent.'

Serbian (see 8)

Bulgarian

13. ${ }^{*}$ Ivanovijat $_{i}$ papagal nego $\mathbf{~}_{\mathrm{i}}$ uhapa včera.

Ivan poss the parrot him bit yesterday

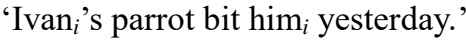

Macedonian

14. *Jovanoviot ${ }_{\mathrm{i}}$ papagal $\mathrm{go}_{\mathrm{i}}$ grizna nego $\mathrm{o}_{\mathrm{i}}$ včera.

Jovan ${ }_{\text {Poss }}$ the parrot him CL bit him yesterday

'Jovan' $i$ 's parrot bit him $_{i}$ yesterday.'

Third, possessive particle is needed in some Asian languages. For instance, Chinese, Japanese and Korean have neither the English clitic nor Slavic possessive case marker; instead, they use possessive particle to indicate possession. For these languages, the binding of prenominal possessive NP and pronoun is impossible.

Chinese (see 6)

Japanese

15. *ジョン ${ }_{i}$ のお父さんは彼 ${ }_{i}$ が賢いと思っている.

John Poss father him intelligent consider

' $\mathrm{John}_{i}$ 's father considers $\operatorname{him}_{i}$ intelligent.'

Korean

16."존은 ${ }_{i}$ 아버지가생각에그는 ${ }_{i}$ 총명하다.

John Poss father consider him intelligent.

'John ${ }_{i}$ 's father considers $\operatorname{him}_{i}$ intelligent.'

Germanic languages like French, Portuguese, Spanish and Italian will use the preposition to indicate possession, quite similar to the English "-of" structure. All these languages allow binding for possessive NP.

French

17. Le père de $\mathrm{John}_{i} \mathrm{le}_{i}$ trouve intelligent.

the father of John him finds intelligent

'The father of $\mathrm{John}_{i}$ finds himi intelligent.'

Portuguese

18. O pai ${ }_{i}$ do Joào consìdera-o $\mathrm{O}_{i}$ inteligente.

the father of John consider him intelligent

'The father of $\mathrm{John}_{i}$ finds $\operatorname{him}_{i}$ intelligent.'

Spanish

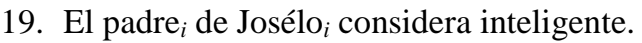

the father of John himconsider intelligent

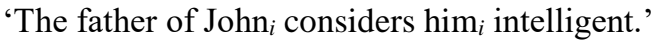

Italian

20. Il padre di Giovanni $i_{i} \operatorname{lo}_{i}$ considera intelligente.

the father of John him considers intelligent

'The father of $\mathrm{John}_{i}$ considers him ${ }_{i}$ intelligent.'

\section{Working Mechanisms for Dual Anaphor}

According to binding condition A and B, a pronoun can be bound by an antecedent and a reflexive must be bound by an antecedent, which means both the reflexive and the pronoun can be anaphors. This dual anaphor (Pollard and Sag, 
1992: 261-303) is a phenomenon commonly found in different languages. As the statistics shows, among almost 5000 languages in the world, the dual anaphor phenomenon could be met in more than 4000 languages (Thompson, 2014). Although the binding principle might help explain some linguistic phenomena, it fails to pinpoint the subtle differences of the working mechanisms that are essential to access the defining property leading to binding possibilities.

Both Kayne (2002) and Boeckx, Norbert and Jairo (2007) attempted to specify the working mechanisms of dual anaphor with different approaches.

Kayne's (2002) approach mainly concerns the anaphor phenomenon of pronoun by first establishing the co-reference pair and then moving the antecedent NP. The derivational process of the anaphor phenomena in sentence 21 is illustrated in sentence 22 .

21. John thinks he's smart.

22. a. thinks [John he] is smart b. $\mathrm{John}_{i}$ thinks $\left[\mathrm{he}_{i}\right]$ is smart.

The derivational process is briefly that, "John" and "he" first establish a co-reference pair, "John" then moves to an external argument position outside the inner CP domain. Otherwise, the illegitimacy of sentence 23

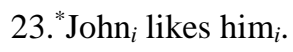

can be explained as the result of lacking a specifier position in vP to locate the moved NP "John", since the co-reference pair [John him] is first located in complement position. Thus, "John" fails to cyclically move to its destination. The situation can be improved in sentence 24 ,

24. John likes himself.

by following Kayne's (2002) train of thoughts that co-reference pair [John him] functions as an NP in DP domain of [John him]'s self, there is a specifier position allowing for the cyclical move of NP "John".

However, Kayne's (2002) approach does little to explain the syntactic truths revealed in sentence 25 and 26.

25. $\mathrm{John}_{i}$ thinks that Mary likes $\operatorname{him}_{i}$.

26. *John thinks himself is smart.

In 25, the co-reference pair [John him] is first located at vP complement position, how can NP "John" cyclically move to the external argument position outside the inner CP domain? In 26, [John him] is also located at a specifier position of DP, then, how can "John" fail to cyclically move?

Boeckx, Norbert and Jairo (2007) proposed a different approach, i.e., a copy and remerge approach, to the reflexive anaphor by examining the language of San Lucas Quiavini Zapotec (abbreviated as SLQZ), a tribe in Brazil and the language of Hmong, minorities in south west China.

SLQZ

27. a. R-yu'lààa'z-ëngla'anng.

HAS-like-3SG.PROX 3SG.PROX

'She/He liked her/him-self.'

b. R-yu'lààa'zGye'eihllyGye'eihlly.

HAS-like MikeMike

'Mike liked himself.'

Hmong

28. a. Nwgyeejqhuasnwg.

3SG always praise $35 \mathrm{G}$

'He always praises himself.'

b. PovyeejqhuasPov. Pao always

praise Pao

'Pao always praises himself.'

The above sentences suggest that the reflexive anaphor is possibly formed by copying and remerging the antecedent 
NP. Thus, for Boeckx, Norbert and Jairo (2007), the English sentence "John likes himself" can be derived as sentence 29

\section{9. [TP John2 [T’T [vP John [VP likes John1-self]]]]}

As Boeckx, Norbert and Jairo (2007) suggested, "self" here did not serve as a morpheme indicating anaphor, since anaphor has already been realized through the syntactic operations of copy and remerge. The syntactic function of "self" is to assign case to NP "John". The reason that "John self" is not allowed is that English "self" could only be a suffix, and the pronoun form "him" entered the derivation as a last resort.

The challenges against Boeckx, Norbert and Jairo's (2007) arguments lie in the followings. First, a thorough examination of sentence 27a shows that the third person pronouns have different forms in internal and external argument positions, and therefore, the operational pattern of copy and remerge is not strictly followed. And second, in sentence 29, suppose John1 and John2 are the same, how can it be assigned case twice in the same CP domain? (Chomsky, 1981) The third concerns the binding possibilities under discussion, in languages where possessive is formed by inserting possessive case marker, if the possessive form of NP appears at the co-reference pair, how is this possessive form allowed? And if not, how can a pronoun appear in different forms in the same CP domain?

Taken together, by establishing co-reference pair in this study, we aimed at realizing the semantic co-reference relation by putting the pronoun and its antecedent together. After the construction of the co-reference pair, the following derivations for reflexive anaphor and pronoun anaphor can be different. It is assumed that the co-reference pair like [John he] in "John thinks that he is intelligent." is unmarked pair, since in this pair, only semantic co-reference relation is established; while no syntactic operation at the interface is implemented. On the contrary, the co-reference pair like [John himself] in "John likes himself." is marked pair, since in this pair, both the semantic operation and the syntactic operation are involved.

In the pair of [John himself], the suffix "self" is a marked form (Gundel, Houlihan and Sanders, 1986), which functions more or less as a corpus verb. Through "self", the identical relation between "John" and "him" is established. Meanwhile, "self" is in charge of assigning an accusative case to the pronoun. In this sense, the pair is quite similar to a CP structure "John is him". If the pair is temporarily considered as a DP, this is the equivalence of a DP to a CP. This same type of equivalence can be found in DP [the enemy's destruction of the city] and CP [the enemy destroyed the city] (Barbara, 2011). Immediately after the pair is constructed, "himself" has got its proper form and "John" has to be moved through the specifier position of DP [John himself] to the closest DP head position that c-commands "himself" in a local domain. Besides the traditional defined local domain and c-commanding relation, two points are still worthy of serious consideration. First, the moved antecedent should be located at a DP head position as can be seen in

30. The friend of John considers himself intelligent.

In sentence 30, the antecedent of "himself" should be "friend" instead of "John", since only "friend" is located at a head position. Second, the antecedent ought to move to the closest head position in relation to the economical principle. As has been mentioned, the co-reference pair containing a reflexive is a marked pair, suggesting that a more complicated syntactic operation has been implemented in the pair itself. Therefore, in the following derivation, the move operation of the antecedent should follow the economical principle to reduce processing load of the language faculty, and the closest move track can be a satisfactory way.

Thus, the following mechanism is put forward for the reflexive anaphor,

\section{Mechanism 1}

The antecedent and the reflexive first establish a marked co-reference pair, and the reflexive suffix assigns a case to pronoun root in this pair. The antecedent then moves to the closest head position that c-commands the reflexive in the local domain in order to satisfy the economical principle.

The pair of [John him] is different. In this unmarked co-reference pair, the semantic co-reference relation is established through the mechanism of unstressed pronoun, not of the corpus-verb-like reflexive suffix. It is observed that in many languages, an unstressed pronoun can be put immediately after a NP, and they have the same reference (Bobaljik, 1996). For example, the Chinese sentence 31 and 32

\section{1. 约翰他 (unstressed) 很喜欢. \\ Yuehan ta (unstressed) henxihuan}


'John likes (it) very much.'

32. 约翰他 (stressed) 很喜欢.

Yuehan ta (stressed) henxihuan

John he very like

'He likes John very much.'

As can be seen from the contrast between sentence 31 and 32, the Chinese third person singular pronoun 他 (ta, 'he') can be put immediately after the antecedent to mean "John" when it is pronounced in an unstressed way. Though the surface form of a pronoun immediately after a NP is almost not allowed in English, this mechanism, at least, can be adopted in the derivational analyses of the pronoun anaphor.

The pair is unmarked simply because there is no exceptional syntactic operation involved. The pair is temporarily constructed only to check the semantic co-reference relation. After the construction, the pronoun remains at its original position to be appropriately assigned a case, and the antecedent NP moves to a position where it can be assigned a case. There can be two possibilities for the possible location of the moved antecedent. On one hand, if it is within the CP domain, the position must still be a c-commanding position except for the closest c-commanding head position which is deliberately left for marked co-reference pair as required by mechanism 1 . On the other, if it is outside CP domain, as has been clearly indicated in phase theory, though CP constitutes natural barrier for syntactic move, c-commanding is still the very foundation of binding (Chomsky, 2001) as illustrated in sentence 33, 34 and 35.

33. John considers himself intelligent.

34. John's father considers him intelligent.

35. John thought that he was intelligent.

In sentence 33 and 34, "John" and the pronoun are in the same CP domain. In sentence 33, "John" is at the closest c-commanding position as predicted by Mechanism 1. In sentence 34, "John" c-commands "him", which is not located at the closest c-commanding head position. Thus, "him" can possibly refer back to "John" for c-commanding relation. In sentence 35, "John" and the pronoun are not in the same CP domain, the c-commanding relation between them does exist, "John" can possibly bind "he".

The pronoun anaphor could be predicted by the following mechanism:

\section{Mechanism 2}

The antecedent and the pronoun first establish an unmarked co-reference pair, and the antecedent then moves to the c-commanding position, but not the closest head one within a CP domain or outside CP domain.

In the subsequent section, the cross-language variation of possessive NP binding possibilities will be carefully examined by strictly following mechanism 2 .

\section{Cross-linguistic Variation of Possessive NP Binding Possibilities}

\subsection{English}

The clitic "-'s" and the "-of" structure to indicate possession are allowed in English. Specifically, the derivation tree for sentences "John's father considers him intelligent" and "The father of John considers him intelligent" are schematically illustrated below.

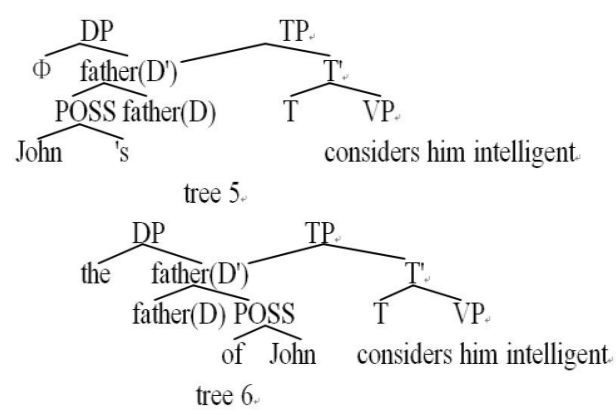

Three points worthy of mention here are first the mirror image approach is adopted. This approach has been used to 
analyze the typological variation of $\mathrm{V}$ head and $\mathrm{V}$ final languages in that both of two structures can be considered the mirror image of each other (Alexiadou, 1998: 491-539). This applies for the English clitic "-'s" structure and "-of" structure. From the above trees, both of them are the mirror image of each other and this can ensure that in both structures, NP "father" can be located at head position. "Father" is located at the closest head position which c-commands "him", according to mechanism 1, "father" and "him" cannot co-refer each other. And this derivational pattern can also solve the contradiction caused in sentence 10 and 11, if the traditional derivation pattern is observed where both "father" and "John" are located at the DP bottom layer, "father" succeeds but "John" fails in establishing co-reference relation with "himself". Second, in both sentences, "John" and "him" can establish co-reference relation as a result of mechanism 2. For tree 5, the c-commanding relation between "John" and "him" can be easily discerned, since it is in accordance with the traditional c-commanding pattern but for tree 6 , the c-commanding relation still exists, though it seems to divert from the traditional pattern. The key to understanding this c-commanding relation lies in that the derivation of DP in tree 6 is the mirror image of that in tree 5, which will not change the semantic c-commanding relation.

For those that form the possessive DP by means of prepositional phrases, e.g., French, Portuguese, Spanish and Italian, the same derivational pattern like tree 6 could be applied as predicted by mechanism 2 in that possessive NPs are all located under the head NP that can make sure the c-commanding relation and not the closet head.

\subsection{Chinese}

Possessive particles are often sought for to constitute possessive DP. For instance, the derivational tree of Chinese sentence“小明 $i$ 的爸爸认为他 $j$ 聪明 (Xiaomingde baba renwei ta congming, 'Xiaomingi's father considered himj intelligent.')" is presented below.

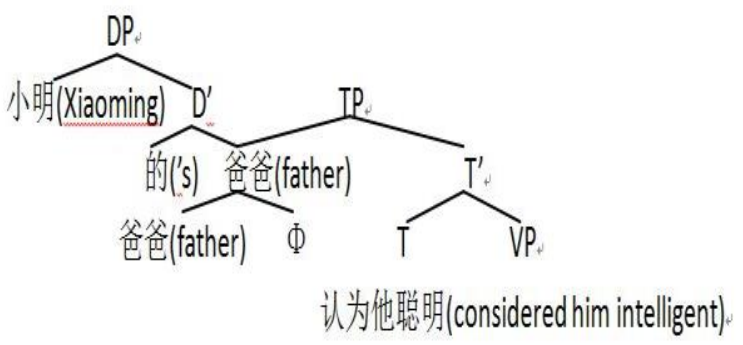

tree 7

As Si (2004: 26-34) puts it that, the Chinese possessive particle is considered to be the head of the possessive DP. Thus the possessive DP “小明的爸爸 (Xiaomingde baba, 'Xiaoming's father')” is derived in this way.

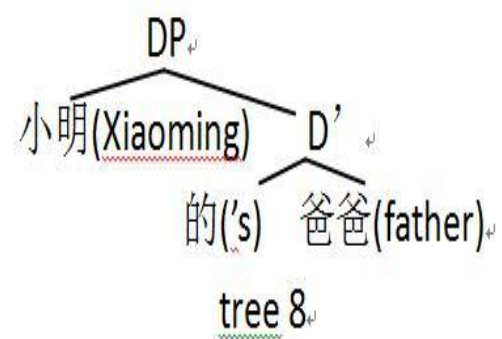

However, this derivational pattern has its own problem in terms of c-commanding relation. If the pattern is followed,爸爸 (baba, 'father')cannot be the head. In order to solve the problem, a small variation to the traditional pattern that locates 爸爸 (baba, 'father') at a closest head position c-commanding 他 (ta, 'him') in VP domain is made to insert one level higher than NP 爸爸 (baba, 'father'). As a consequence, if 爸 (baba, 'father') co-refers with 他 (ta, 'him'), the reflexive form 他自己 (taziji, 'himself') has to be used instead. Here, 小明 (Xiaoming) is thought to occupy the specifier position of DP simply because that no other modifier element can be added. Thus, Chinese 36

36. *这个小明的朋友.

thisXiaoming's friend 
'This Xiaoming's friend.'

is unacceptable. By contrast, the English sentence "this John's friend" is grammatical, since the specifier position of DP in English is empty. Meanwhile, 小明 (Xiaoming) fails to c-command 他 (ta, 'him') as can be seen from tree 8, and thus 他 (ta, 'him') cannot refer back to 小明 (Xiaoming), which is also true of some languages, e.g.,Japanese and Korean.

\subsection{Russian}

As one of north Slavic languages, Russian, different from other south Slavic languages, constitutes possessive by adding possessive case marker. Russian possessive NP is post nominal instead of pre-nominal. It is assumed in the presentstudy that the Russian sentence “ Отец Джона

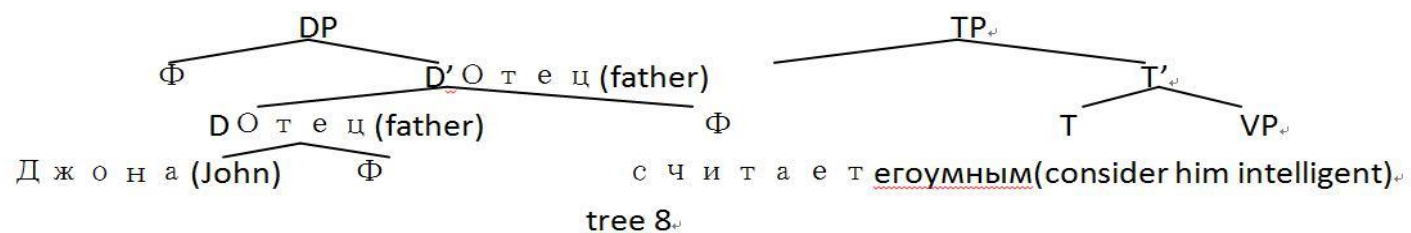

It can be clearly shown in this derivation, "Отец" (father) is located at the closest c-commanding head position of DP domain, and consequently, "Отец" (father) and "его" (him) cannot co-refer; otherwise, the reflexive form should be used. “Джона" (John) and “его” (him) can co-refer in that “Джона" (John) is not located at that closest c-commanding head position that properly c-commands "его" (him). As has been defined in phase theory (Chomsky, 2001), in a minimal pair like [he is], "he" semantically checks the singular meaning of be verb and be verb syntactically checks the nominative case of "he". This applies to the minimal pair [Отец Джона] ([father John]). “Джона” (John) semantically identifies the possessive relation and “Отец" (father) syntactically check the possessive case.

\subsection{Serbian}

In possessive case-marked language like Serbian, NP in TP domain is not allowed to refer back to pre-nominal NP, which can be clearly explained by the following derivational process of the Serbian sentence "Markovi otac smatra njegai veoma pametnim" in tree 9 .

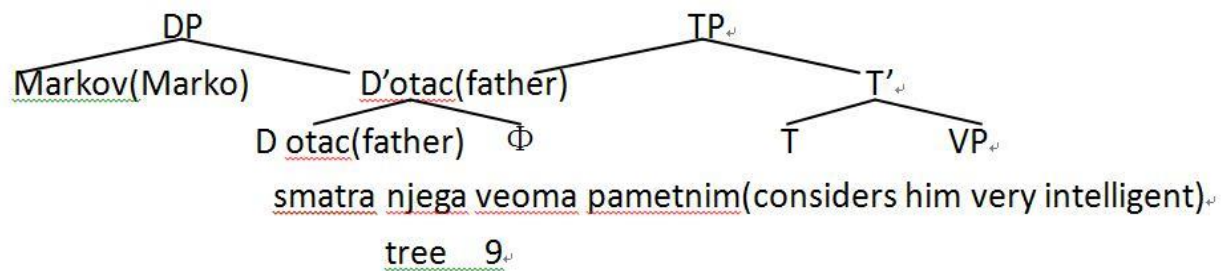

In this derivation, "otac" (father) is located at the closest c-commanding head position, suppose it refers back to this "otac" (father), like all other languages, the pronoun in TP domain ought to have reflexive form. "Markov" (Marko) is located at the specifier position of DP, which fails to c-command "njega" (him), leading to the failure of binding relation between "Markov" (Marko) and "njega" (him). It explains the impossibility for "njega" (him) to co-refer with "Markov" (Marko) in turn. Besides, this derivation pattern also explains why co-reference is still not allowed even the modifier "ovaj" (this) is inserted before the pre-nominal possessive NP. As can be clearly conveyed by the pattern, the insertion of modifier cannot make possessive NP c-command the pronoun in TP domain. The same derivation pattern could also be found in south Slavic languages like Bulgarian and Macedonian.

As a summary, in this section, through the careful cross-linguistic examination of the binding possibilities associated with their derivational patterns, it can be discovered that principles and parameters co-exist cross-linguistically. The principles lie in semantic c-commanding relation and syntactic distance. And the semantic c-commanding relation between syntactic elements is the prerequisite for both obligatory and optional binding. The closest syntactic distance can make sure the obligatory binding as has been mentioned with the aid of economy principle. The parameters reside in that possessive NP c-commands pronoun for some languages, then binding is possible; otherwise, possessive NP does not c-commands pronoun for some other languages, binding will surely be impossible.

One point to notice is that present study altered traditional derivation pattern of supposing $\mathrm{T}$ always enter derivation 
after the completeness of DP derivation (e.g., Bobaljik, 1996). Instead, T enters derivation always at the stage of when the head of the possessive DP first occurs. This speculative theoretical practice might ensure that mechanism 1 successfully works and the possessive NP may enter derivation either before or after this stage which in turn cause binding possibility variations.

Another point to notice is all the above analyses can also be applied to the cross-linguistic variation in the long-distance binding possibilities between the pronoun in inner $\mathrm{CP}$ domain and the possessive NP in outside $\mathrm{CP}$ domain since the success or failure in establishing the c-commanding relation is the same as exemplified by 37 and 38 .

37.John ${ }_{i}$ 's father thinks that he ${ }_{i}$ can do the job.

38. *小明 $i$ 的爸爸认为他 $i$ 能做这项工作.

Xiaomingde baba renwei ta neng zuo zhexing gongzuo

Xiaoming poss father think he can do this job

'Xiaoming ${ }_{i}$ 's father thinks that he ${ }_{i}$ can do the job.'

\section{Conclusion}

There exists parameter difference of binding possibilities between the possessive NP and the pronoun cross-linguistically. Some earlier studies explained such difference with parameterized DP approach, i.e., for languages possessing DP layer, binding is possible on the condition that possessive NP fails to c-command pronoun. It is observed in the present study that, the specific examples from Serbian indicate the insertion of DP layer cannot deal with grammaticality of the sentences. Consequently, echoing such debate, based on the linguistic data provided, the present study examined the difference from c-commanding relation. After discussing different mechanisms of obligatory and optional binding, we found that within the CP domain, binding possibilities have nothing to do with DP layer, but are decided by c-commanding as c-commanding is the semantic basis of binding relation. For obligatory binding, the antecedent is located at the closest head position c-commanding the anaphor that requires the anaphor in reflexive form. And the antecedent is not located at that closest head position but still c-commands anaphor for optional binding. Besides, we also found that different binding possibilities are the result of whether the possessive NP as an antecedent succeeds or fails in the establishment of the c-commanding relation with anaphor. Across different languages, $\mathrm{T}$ enters derivation at the stage of the appearance of head NP to make sure that head is located at the closest head position. On the contrary, for languages whose possessive NP enters before T, it succeeds in establishing c-commanding relation, and thus, the binding is possible; and for languages whose possessive NP enters after T, it fails in establishing c-commanding relation so that the binding is impossible.

To the best of our knowledge, much space of theoretical improvement work concerning binding possibilities should be done, given that the present study is a tentative attempt, specifically, considering that binding problems are very tricky, those situations where possessive NP is in pronoun form should be concerned in the future study.

\section{References}

Alexiadou, A. (1998). Parametrizing AGR: Word order, v-movement and EPP-checking. Natural Language \& Linguistic Theory, 16(3), 491-539.

Barbara, C. (2011). Symmetry in Syntax Merge, Move, and Labels.New York:Cambridge University Press.

Bobaljik, J. D. (1996). Subject positions and the roles of TP. Linguistic Inquiry, 27(2), 195-236.

Boeckx, C., Norbert, H., \& Jairo, N. (2007). Overt copies in reflexive and control structures: a movement analysis. In: Jing, A.C.C., C. Nakao, E. Takahashi (Eds.). University of Maryland Working Papers in Linguistics (vol. 15). College Park, MD: UMWPiL.

Boskovic, Z. (2009). More on the no-DP analysis of article-less languages. Studia Linguistica, 63,187-203.

Chomsky, N. (1981). Lectures on government and binding. Language, 60(2), 670-699.

Chomsky, N. (2001). Derivation by phase. In M. Kenstowicz (Ed.). Ken Hale: A Life in Language. Cambridge, MA: MIT Press.

Despic, M. (2011). Syntax in the Absence of Determiner Phrase. Doctoral dissertation, University of Connecticut, Storrs.

Despic, M. (2013). Binding and the structure of NP in Serbo-Croatian. Linguistic Inquiry, 44(2), 239-270. 
Fukui, N. (1988). Deriving the differences between English and Japanese. English Linguistics, 5, 249-270.

Gundel, J. K., Houlihan, K., \& Sanders, G. A. (1986). Markedness and Distribution in Phonology and Syntax. In: F. R., Eckman, E. A., Moravcsik, J. R., Wirth (Eds.). Markedness. Springer, pp.107-138.

Kayne, R. (1994). The Anti-symmetry of Syntax. Cambridge, MA: MIT Press.

Kayne, R. (2002). Pronouns and their antecedents. In: S. Epstein, T. Daniel (Eds.). Derivation and Explanation in the Minimalist Program. Malden, MA: Blackwell, pp.133-167.

Laterza, I. (2016). Binding in English and south Slavic and the parameterized DP hypothesis. Linguistic Inquiry, 47(4), 741-753.

Lowe, J. J. (2015). English possessive's: Clitic and, affix. Natural Language \& Linguistic Theory, (1), 1-39.

Pollard, C., \& Sag, I. A. (1992). Anaphors in English and the scope of binding theory. Linguistic Inquiry, 23(2), 261-303.

Si, F. (2004). The head theory and the Chinese de Phrase. Modern Linguistics, 1, 26-34.

Thompson, A. (2014). Beyond Deep and Surface: Explorations in the Typology of Anaphora. Dissertations \& Theses - Gradworks.

Wang, Y., \& Xu, J. (2013). A systemic typology of existential and possessive constructions. Functions of Language 20(1), 1-30.

Webelhuth, G. (1995). Government and Binding Theory and the Minimalist Program: Principles and Parameters in Syntactic Theory. Blackwell.

Zlatic, L. (1997). The Structure of the Serbian Noun Phrase. Doctoral dissertation, University of Texas at Austin. 